\title{
A Decolonial Imagination: Sociology, Anthropology and The Politics of Reality
}

\begin{abstract}
While the recent proliferation of sociological engagements with postcolonial thought is important and welcome, central to most critiques of Eurocentrism is a concern with the realm of epistemology, with how sociology comes to know its objects of study. Such a concern, however, risks perpetuating another form of Eurocentrism, one that is responsible for instituting the very distinction between epistemology and ontology, knowledge and reality. By developing a sustained engagement with Boaventura de Sousa Santos's work, as well as establishing possible connections with what has been termed the 'turn to ontology' in anthropology, in this paper I argue that in order for sociology to become exposed to the deeply transformative potential of nonEurocentric thinking, it needs to cultivate a decolonial imagination in order to move beyond epistemology, and to recognise that there is no social and cognitive justice without existential justice, no politics of knowledge without a politics of reality.
\end{abstract}

Keywords: Anthropology, Decolonial Thought, Epistemologies of the South, Eurocentrism, Imagination, Kant, Ontology, Reality, Sociology

\section{Author Details:}

Martin Savransky

Department of Sociology

Goldsmiths, University of London

London SE14 6JW

United Kingdom

m.savransky@gold.ac.uk

\section{Introduction}

Over the past forty years, scholars in the humanities and the social sciences have provided powerful and sophisticated post-colonial and de-colonial critiques of the relationships between the conceptual, epistemological and methodological premises of Western modes of knowledge-production, and European projects of colonial expansion (for classical instances Said, 1978; Spivak, 1988; Bhabha, 1994; more recently, see Chakrabarty, 2000; Mignolo, 2011; Seth, 2013; Wallerstein, 1996). These critical lessons, however, have been rather hard-won in sociology ${ }^{1}$. Gurminder Bhambra (2007a) has argued that, due to the discipline's commitment to what are seen as the core values of modernity, the sociological engagement with postcolonial thought has been reduced to the rather liberal gesture of a pluralisation of 'others' both other sociological traditions and other 'modernities' (e.g. Eisenstadt, 2000)- 
while remaining immune to the decentering and transformative challenges that such modes of thought pose to the core premises of sociological forms of understanding, explaining, and theorising. In the spirit of Bhambra's call for sociology to become exposed to such challenges, this article argues that exposure to the difference that decolonial thought makes can not only transform how sociological knowledge is produced, but what we take sociology to be.

While Bhambra's diagnosis is still largely descriptive of the contemporary relations between sociology and postcolonial thought, in the last few years the former's immunity to the latter has also begun to show some signs of erosion. Sociologists of different parts of the world have been actively involved in mounting challenges to sociology's Eurocentric premises by attempting to open up social theory's canon (Connell, 2007), decolonising social research methodologies (Denzin et al., 2008), challenging sociology's historical account of modernity (Bhambra $2007 \mathrm{~b}$; 2014) and, centrally to all these projects, questioning the discipline's epistemological presuppositions (Go, 2013, Keim et al. 2014; McLennan, 2006; Gutiérrez Rodríguez et al., 2010).

The question of epistemology, that is, of how European sociology -and the social sciences more generally- comes to know and represent its objects of study, has indeed been the common thread across the aforementioned projects and in many of the works of scholars in both postcolonial and decolonial traditions (see Savransky, 2012). In this way, these projects have shown the necessary inadequacies, exclusions, and marginalisations that result of any attempt at producing knowledge of nonEuropean experiences by imposing sociology's own epistemological categories, and they have argued for the need to develop alternative theories of knowledge that emanate from, and be grounded in, those experiences.

In this context, the work of Boaventura de Sousa Santos (1992, 2007, 2008, 2014), that provides a partial framework for this special issue and which constitutes the central focus of this article, is exemplary. Concerned for over two decades with the deep entanglements between struggles for social justice and forms of cognitive justice, he has developed not only a poignant critique of the 'northern epistemologies' associated with modern science but also proposed a plethora of concepts for the construction of an insurgent sociological imagination that affirms that 'the understanding of the world by far exceeds the Western understanding of the world' and thus seeks to cultivate an 'ecology of knowledges' (Santos, 2014: viii). In this way, he has become one of the leading voices in the articulation of a decolonial break 
from the Eurocentric epistemology of the social sciences and has most recently sought to frame his project under the sign of 'epistemologies of the South' (Santos, 2014).

The emphasis on epistemology as the register par excellence on which to situate a politics of knowledge -an emphasis that, as said, runs across postcolonial and decolonial critiques within and outside sociology- is not, however, without its dangers. For although it may succeed in challenging the epistemological Eurocentrism that pervades modern European sociology and indeed the modern sciences as a whole, it still rests on the very modern, European image of thought that takes for granted the existence of a fundamental distinction, or what Santos (2014) calls an 'abyssal line', between epistemology and ontology, knowledge and reality. As I shall show, this abyss, which can be traced all the way back to Immanuel Kant's 'Copernican Revolution', has shaped not only the modern sciences but also most of the Western philosophical imaginations on which both conventional and critical approaches to social science have been built.

I will argue that the reliance by postcolonial and decolonial thought on such a distinction risks producing another kind of Eurocentrism, namely, a metaphysical one (Savransky, 2014). Given this danger haunting the possible futures of a global sociology, the aim of this paper is to make a conceptual contribution to the insurgent sociological imagination that Santos's (2014) calls 'postabyssal thought' by proposing that, in addition to the development of epistemologies of the South by way of an ecology of knowledges, what traversing the Western abyss requires is the cultivation of a decolonial imagination. One that may enable a global sociology to move beyond the very abyssal line that bifurcates knowledge from reality, or 'epistemology' from 'ontology', and to reorient itself not just toward a decolonisation of knowledge, but also of reality.

After providing an in-depth exploration of the emergence and profundity of the colonial abyss and how it limits epistemological forms of critique, I will further clarify some of the implications of cultivating a different sociological imagination by paying attention to what has been called the "turn to ontology" in contemporary cultural anthropology (see for instance Alberti et al., 2011; Carrithers et al. 2010; Holbraad, 2012; Viveiros de Castro, 2003, 2014). I shall suggest that, while this recent turn in anthropology is not without its limitations, a closer engagement between sociology and anthropology is imperative for the cultivation of a decolonial imagination. To the extent that the task of a post-abyssal sociology may be to learn from the social and political practices of subaltern countermovements of the global South in the struggle 
for forms of social and cognitive justice (Santos 2014), a decolonial imagination can contribute to making sociology sensitive to the fact that at stake in many of such struggles is the constructive, political affirmation of 'alter-ontologies' (Papadopoulos, 2010): of alternative -and often suppressed, silenced and marginalised- realities. In other words, a decolonial imagination involves the assertion that, to add to one of Santos's (2014) guiding propositions, there is no social and no cognitive justice without existential justice. There is no politics of knowledge without a politics of reality.

If Santos's work is exemplary, however, it is because it also points to a possible line of escape from the Kantian paradigm. Unlike what is apparent in the work of many scholars in postcolonial studies or indeed in the 'coloniality/modernity' programme, where epistemology is often seen as the ultimate horizon of any critical intervention worthy of its name (e.g. Quijano, 2007; Mignolo, 2011), I shall argue that within the vocabulary that Santos develops in order to devise alternatives to northern sociologies, one can already begin to envisage the seeds of a decolonial sociological imagination in the making. Thus, I will suggest that his concept of the 'sociology of absences', if read in a radically realist sense, can become a potentially fertile, alternative locus from which to cultivate non-abyssal forms of sociological thought and knowledge.

\section{Down The Colonial Abyss: The End of Epistemology Without End?}

Ever since his 'Discourse on the Sciences' (1992), the work of Santos has been concerned with the project of a reassessment of the processes by which Western, modern, scientific rationality has become associated with a universal virtue, while simultaneously turning every other form of rationality not just into cases of error but into the very definition of what that is 'irrelevant, illusory, and false.' (Santos, 1992: 11). More than a scholarly interest in the history of scientific knowledge, Santos's is an ethical and political project of taking seriously the critical question of what kinds of social, cultural and political life such forms of knowing have made available at a global scale, and at what cost. No response to such a question can be reduced to the demand for "better" modern science, for the contrast the question poses is a qualitative one. It is one that demands, first, the articulation of a critical stance regarding the very foundations on which modern, Western thought is built. Second, the reclaiming of old, 
and the developing of new, modes of understanding (Santos 2008) for the construction of an entirely different kind of knowledge 'that does not separate us from, but rather connects us personally with, whatever we study' (Santos, 1992: 42).

One of the concepts that Santos has developed in order to critically diagnose the very nature of Western, modern thought is that of 'the abyss'. According to this metaphor, Western thought is largely an abyssal form of thought, founded on 'a system of visible and invisible distinctions, the invisible ones being the foundation of the visible ones.' (Santos, 2014: 118). While the image of Western modern thinking as a binary thought that thrives in distinctions, classifications and taxonomies is well known, the abyssal lines that Santos rightly associates with it are even more foundational, such that whatever is forced to belong to " the other side of the line" vanishes as reality, becomes nonexistent, and is indeed produced as nonexistent.' (Santos, 2014: 118). Unlike the modern habits of binary distinctions, such abyssal lines remain comparatively invisible, yet they constitute the very foundation on which Western binary thinking rests.

As Santos (2014: 119) explains, modern knowledge constitutes one of the spheres that is most conspicuously traversed by such lines. ${ }^{2}$ The visible abyssal line that pervades modern knowledge is at the core of disputes over the demarcation between scientific and non-scientific forms of knowledge. Concretely, it belongs to the distinction between modern science, with its 'monopoly of the universal distinction between true and false' on 'this' side of the line, and the knowledge produced by philosophy and theology, on the other. But such distinctions are only the more visible ones, operating within a Eurocentric academic system that, despite its constant threats to the institutional futures of philosophy and theology, already accepts them as legitimate -if not necessarily as 'true', or as 'reliable'- forms of modern knowledge in the first place (Santos, 2014: 120).

As such, they themselves represent only one side of a more foundational, and less visible abyss. That is, the colonial abyss that separates Western, modern knowledges- some 'truer' than others, some more 'rational' and 'reliable' than others- on "this" side of the line, from the entire "realm of incomprehensible beliefs and behaviours that in no way can be considered knowledge, whether true or false', on the other. These are practices constituted by non-modern, lay, peasant, and indigenous forms of thinking, knowing and feeling, that are 'rendered incommensurable and incomprehensible for meeting neither the scientific methods of truth nor their 
acknowledged contesters in the realm of philosophy and theology.' (Santos, 2014: 120)

The depth of the colonial abyss cannot be underestimated. For the abyssal image has not only infected conventional political and epistemological thinking in the West, but also its critical versions. Indeed, expanding considerably on a seminal observation by Aníbal Quijano (2007), Santos argues that because post-Marxist critical theory remains fundamentally anchored on a Western-based discourse of universal human rights, it 'reduces the understanding of the world to the Western understanding of the world, thus ignoring [...] decisive cultural and political experiences and initiatives in the countries of the global South.' (Santos 2014: 21). Such abyssal ignorance situates contemporary critical discourses in something of a historico-theoretical paradox where, at a time when crises of diverse natures and scope proliferate, their critical political imagination has never been more ill-equipped to provide productive answers to the strong questions through which our global social and political futures are brought into existence. Questions, in other words, that amount to the demand to imagine, simultaneously, the end of capitalism and the end of colonialism; questions for which critical theory has nothing but weak answers (Santos 2014: 24-27).

Although it is as difficult to imagine the end of capitalism and of colonialism as it is to imagine that they have no end-which is to say, that they are outside history(Santos, 2014: 24) such imaginative impasses nevertheless seem to have a paralysing effect on critical thought. This paralysis is explained, according to Santos, by the Eurocentric epistemology informing Marxist and post-Marxist thought. Thus, while critical theory developed historically in the global North and is hence traversed by the colonial abyss, the most transformative left practices of recent times have been born in the global South, 'carried out by strange people who often speak very strange noncolonial languages $[\ldots]$ or less hegemonic colonial languages [...] and their cultural and political references are non-Western'(Santos 2014: 41).

Given the colonial abyss's pervasive capacity to infect the practices of critical sociological projects, Santos's project of another knowledge for a different kind of social, cultural and political life, consists, consequently in a 'rearguard' theoretical construction that creates the conditions required to 'capture the immense variety of critical discourses and practices and to valorise and maximize their transformative potential' (Santos 2014: 42). Conditions that demand an 'epistemological reconstruction' (Santos 2014: 42) that would break with northern epistemologies 
while 'amplifying the intensity of this sound [i.e. the sound of the demands for social and cognitive justice by the anti-imperial global South] by exploring the different epistemological dimensions of the claims being made.' (Santos 2014: 237).

While I strongly support Santos's project of an engagement with epistemologies of the South, I would like to make a contribution to it by posing yet another strong, difficult question: what if the colonial abyss goes even deeper? Indeed, what if this epistemological line is not invisible enough, concealing its own foundation upon yet another abyssal line, just as modern, just as Western, which is the very distinction between epistemology and ontology, knowledge and reality? What if the left's incapacity to listen and learn from the sound of demands of the anti-imperial global South is not only the result of an epistemological Eurocentrism that finds others' forms of knowledge incomprehensible, but the result of a deeper, metaphysical Eurocentrism that opposes what these noncolonial languages assume, and does not understand that what is at stake is not only cognitive but existential justice- the cry that a different world is possible, and not just a different knowledge?

The conception of knowledge as actively representing reality, upon which the very importance of epistemology and its central question -what can one know?- are grounded, is in fact a quintessentially modern and Western conception. It is one that can be traced all the way back to Immanuel Kant's (1998) so-called 'Copernican Revolution', where he attempted to reconcile the divide between empiricism and rationalism that through the eighteenth century governed the field of European philosophy by proposing the transcendental doctrine that the mind actively processes -represents- experience in constructing knowledge, instead of disclosing an independent reality.

In producing such a synthesis, however, a profound abyss had also been dugan abyssal line situating any form of knowledge on "this side", and any reality, on the other. For instead of disclosing eternal truths and the nature of God -as rationalists would have it- or indeed, of disclosing aspects of the reality of the world itself -as empiricists would have it- knowledge became the very correlation between the world and the experiencing human subject, between knower and known (Meillassoux, 2008). What we do know, therefore, became a matter of secondary importance in the face of the question of what we can know. It became secondary, that is, to the question of the transcendental conditions of possibility of knowing itself, while simultaneously entailing a 'degradation of the world into 'mere appearance"' (Whitehead, 1978: 49); in other words, into how the world appears to the subject. In this way, there is nothing 
that can be said of the world as such that is not said about the world as represented by human subjects.

As with the epistemological line described above, the impact of this other abyssal line on modern, Western imaginations can hardly be exaggerated. As historians of science Lorraine Daston and Peter Galison (2007: 205) put it in their monumental study on the history of objectivity, Kant's synthesis -which involved a reformulation of the scholastic categories of the objective and the subjective into the modern distinction we have come to take for $\operatorname{granted}^{3}-$ 'reverberated with seismic intensity in every domain of nineteenth-century intellectual life, from science to literature.' Often marked by creative misappropriations and misreadings, echoes of Kant's revolution provoked an enormous shift in the ethos of scientific research, from the metaphysical quest of truth, to the pursuit of objectivity as a distinctly epistemological goal that could guarantee that the inescapable activity of this knowing subject would not jeopardise the objective validity of scientific findings.

The formation of European sociological traditions was, for the most part, not exempt from the Kantian legacy either, often reappropriating Kant's insights by way of Neo-Kantian conceptions that transposed the former's transcendental conditions of the knowing subject into quasi-transcendental or historical, social, cultural and economic conditions. Briefly put, echoes of Kant resonate, for example, in Max Weber's (1949: 81) classical definition of sociology as a science of interpretative understanding of human action, a definition whose basis was no other than 'the transcendental presupposition of every cultural science', namely, that humans are 'cultural beings' that lend significance and assign meaning to an otherwise meaningless world. Durkheim (1965), for his part, swayed between a positivist inheritance that would enable him to assert social facts as 'things' and a neoKantianism that asserted society as the 'substratum' of every form of individual and collective 'representation'. And vestiges of the Kantian method emerge, albeit through a materialist inversion, with Marx's and Engels's (1998: 42) locating of historical modes of production as conditions for the development of social and cultural forms, including the formation of 'consciousness' and 'ideology'.

More directly pertinent to our purposes, however, is the fact that the profundity of the metaphysical abyss created by Kant's correlationist synthesis also stands at the core of the European traditions of critical thought - such as phenomenology, structuralism and poststructuralism- on which the epistemological critiques of modern scientific Eurocentrism often draw (see Braver, 2007). To be sure, postcolonial and 
decolonial projects have contested the epistemological privilege accorded to modern forms of knowledge, thereby challenging the Eurocentric assumption that, unlike nonmodern thought - which often confuses nature with culture, humans with nonhumans, the subjective with the objective- Modernity provides the fully developed conditions for a form of knowledge that may count as universally "rational". In so doing, however, they have also accepted the very same Kantian metaphysical framework for which epistemology becomes a distinct problem- namely, that any and all production of knowledge stems from individual or collective subjects that infuse what they see with their own conditioned presuppositions.

Indeed, to the extent that they criticise Eurocentric assumptions on the basis that they presuppose that the 'knowing subjects [are] also universal' (Mignolo, 2009: 160) and that the exclusions they effect are 'ultimately epistemological' (Chakrabarty, 2000: 98); in other words, to the extent that these criticisms assume that colonial oppression is exerted, 'above all, over the modes of knowing, of producing knowledge, of producing perspectives, images and systems of images, symbols, modes of signification over resources, patterns, and instruments of formalized and objectivised expression, intellectual or visual' (Quijano, 2007: 169. emphasis added), such criticisms cannot challenge the modern, Western epistemological privilege without simultaneously participating in the latter's way of imagining what knowledge is in the first place, and how it connects, or fails to connect, with reality.

In the aforementioned article, Bhambra (2007: 879) suggests that a pluralisation of other voices in sociology 'can never be enough' to release the transformative potential of postcolonial thought unless their emergence calls into question 'the structures of knowledge that have previously occluded' them. In the same spirit, I am arguing here that pluralising other knowledges can never be enough unless their emergence calls into question the metaphysical structures of the imagination that keep the very relationship between epistemology and ontology intact. Otherwise, the attempts to traverse the epistemological abyss may be at risk of going down a deeper one. They are at risk, that is, of relying on a different kind of Eurocentrism that does not simply affect the structures and categories of knowing but the entire mode of imagining the relationship between knowledge and reality. One that enables a sociological engagement with knowledges from the South at the expense of a more radical engagement with the fact that there may well be no such distinction between the knowledges and the realities of the South (Savransky, 2014). 
Thus, if the epistemological Eurocentrism of critical theory demands that we assert that it is as difficult to imagine the end of capitalism and of colonialism as it is to imagine that they have no end, I propose here that the threat of metaphysical Eurocentrism haunting the traditions of postcolonial thought that extend the Kantian legacy also demands, in turn, that we assert that it is as difficult to imagine the end of epistemology as it is to imagine that it has no end. Put differently, it demands of us that we risk imagining an entirely different relationship between knowledge and reality.

In the remainder of this paper I thus seek to explore this demand, and to provide some initial elements for its development. In order to further clarify some of the implications of cultivating a different imagination for sociology, in what follows I shall first attend to the recent efforts by a number of cultural anthropologists that have been involved in a similar task of reshaping the anthropological imagination and, as a result, have called for a 'turn to ontology' in anthropology. I shall suggest that, while the framing of such a 'turn' is not without its own dangers, the possibilities made available by some of this work suggest that today, perhaps more than ever, new alliances between sociology and anthropology are called for. With a view to forging such alliances, in the final section of the article I shall return to Santos's work to suggest that aspects of the latter already contain elements that may enable such a decolonial imagination to be cultivated, and stronger alliances to be forged, even as difficult questions are posed to it.

\section{A Permanent Decolonisation of Thought: Anthropology and The "Turn to Ontology"}

While it may have been born as a direct product of colonialism, devoting its efforts 'to a description and analysis- carried out by Europeans, for a European audience- of non-European societies dominated by European power' (Asad, 1973: 15), for the last four decades anthropology has been not only aware of its implication in colonialism, but actively and critically revisiting its own foundations as a consequence. Indeed, the landmark publication of Writing Culture (Clifford \& Marcus, 1986), which represented a transformative event in the discipline that opened it up to a 'reflexive turn', was also motivated by the realisation that anthropology had been 'enmeshed in a world of enduring and changing power inequalities, [in which] it 
continues to be implicated.' (Clifford, 1986: 9) Surely, the effects that such a turn has had on anthropology -and beyond-are in many ways welcome. The discussion above, however, should make us vigilant of the seamless convergence between the discipline's increasing self-awareness as to its own colonialist underpinnings, and a crisis of representation that turned anthropologists attention to the epistemological premises by which knowledge of other cultures is produced.

Indeed, although it problematised anthropology's conventional ways of mobilising its own modern, Western, truths to explain away the 'beliefs' of 'primitive' others, and forced it to turn its attention toward its own modes of representation and veridiction, the reflexive turn -perhaps we may call it the Kantian turn?- could not provincialise anthropology's truths without simultaneously universalising its own epistemological problem. In other words, while anthropology could no longer be the discipline concerned with knowing the truth about human nature across cultures, it became a study of how cultures, peoples -including anthropologists, but also everyone else-interpret and represent the world.

Despite the overwhelming success of the reflexive turn, in recent years an alternative to anthropology's epistemological obsessions, one that could be seen as emerging in the wake of Eduardo Viveiros de Castro's pioneering ethnography of Amerindian perspectivism (1998), has begun to take the discipline by storm (e.g. Alberti et al., 2011; Carrithers et al. 2010; Holbraad, 2012; Viveiros de Castro, 2003, 2014). In many ways, this alternative, that has received the name of the 'ontological turn', shares with other decolonial projects such as Santos's a similar aim. That is, that of turning anthropology into 'a permanent exercise in the decolonisation of thought' (Viveiros de Castro, 2014: 47-48) by attempting to learn from those others that Western thought has considered irrational or incomprehensible, and doing so in such a way that these others are configured as theoretical agents, as a source of the most interesting concepts, problems, and entities, rather than as mere cultural objects of Western thought and knowledge (Viveiros de Castro, 2004: 4, 2014: 40).

However, unlike the decolonial projects that extend the Kantian legacy -for which this exercise in 'learning from' often involves the paradox of reconstructing an epistemology for people who do not construct it for themselves ${ }^{4}-$ this alternative is animated by a different kind of imagination. It seeks to take the thought of others which is also to say, the reality of others- seriously by 'using it, drawing out its consequences, and asserting the effects it may produce on our own' modern, Western thought (Viveiros de Castro, 2003). As such, it involves a 'recursive' (Holbraad, 
2012), or what I would call a 'speculative' (Savransky, 2016), operation-rather than attempting to think about difference, it seeks to think with the difference that thinking from the South itself makes.

Thus, its task is no longer that of putting non-European realities and the thinking that is cultivated in and from them to the test of modern, Western, thought. Nor is it that of attempting to level the playing field by raising all concepts to the status of representations thereby forcing others to partake in the modern game of epistemology. Instead, such a decolonial, speculative project seeks to put modern, Western, thought to the test of non-modern, non-Western realities, and to experience the transformation of our Western imagination by the radical, decolonising differences other realities, other concepts, and other truths, make.

An illustrative example of this, which deals directly -if only seemingly- with questions of knowledge, can be found in Martin Holbraad's (2012) ethnography of the concept of truth in Ifá practices of divination in Cuba, a concept that is not merely implicitly involved in divination but crucially present, both for practitioners and consultants, as something that matters (Savransky, 2016). The point of departure is the seeming paradox, from the point of view of the West, that "practitioners of divination do not just take the verdicts that oracles deliver to be true, but rather take them to be the kinds of things that could not but be true.' (Holbraad, 2012: 55. emphasis in original). In this way, a '[d]iviner's claim, in other words, is not just to truth, but rather to a kind of truth that has also been something of a holy grail in the Western tradition of reasoning, namely indubitable truth.' (Holbraad, 2012: 55).

That divinatory truth be indubitable is important, and not just because it discloses the radical alterity of diviners' claim in the eyes of a skeptical, secularist, Western anthropologist who may already have a hard time imagining that any relationship between something as dubious as divination, and something as solemn as truth, even exists. It is important because to speak of indubitable truth is, strictly speaking, to eschew the Kantian problem of epistemology altogether. While Holbraad suggests that indubitable truth may be a quintessential element of Western traditions of thought, it is more specifically the holy grail of the rationalist tradition -think of Descartes's method of doubt- in relation to which Kant produced his epistemological revolution. After the Kantian reconciliation, the idea of indubitable truth becomes more like a chimera whose very possibility of achievement is itself foreclosed by the unavoidable problem of how one comes to know anything. If, as argued in the previous section, knowledge in this sense is but the correlation between reality and 
human minds or cultures, truth can only ever be 'doubtful', that is, open, at least in principle, to doubt, to probability, to the conservation of the conditions under which a truth-claim is made, to the possibility of error. Truth is always subject, in other words, to the fundamental dependence by what is known, on who/what knows it. Indeed, once inside the epistemological game, only knowledge -i.e. representations of a fact- can be either true or false, and this knowledge is never the mere reflection of the fact, but always the outcome of the active interpretation, by a knowing subject, of an object known.

How to take divinatory practices seriously, then? As I have shown, traversing the epistemological abyss, claiming that Ifá diviners have a different way of knowing the truth, will not do. What is needed, therefore, is not so much an epistemological reconstruction but an inquiry that allows us to imagine an entirely different relation between knowledge and reality such that Ifá's concept of truth may not just 'make sense', but may become transformative of how truth is conceived in the West too. What is required, in other words, is an inquiry that can grapple directly with the ontology of truth, that is, with the question of what divinatory truth is and how it operates in such practices.

Holbraad's study constitutes just such an inquiry. Although I cannot possibly do justice to the sophistication of his ethnographic exploration within the bounds of this paper, by engaging with divinatory consultations as well as initiation rituals, and indeed with the entire cosmology of Ifá, Holbraad (2012: 203-205) argues that divinatory truth is something other than a representation, grounded as the latter is on the immutable distinction between subject and object. By contrast, divinatory truth emerges as the diviner succeeds in practice in bringing together different, dynamic paths of existence and meaning -e.g. the mythical path of Ifá gods, the meaning emerging of the manipulation of the material powders and paraphernalia during the consultation, and the personal path of the consultant- such that a metamorphosis of all such trajectories is produced. As Holbraad (2012: 207) puts it,

at issue here is not the veracity of the way things are thought about or represented, but rather the capability that things moving, motile things- have to reveal themselves in particular ways, when they come into relation with each other: the affect of proximal motion. Indeed, this should not be read merely as a metaphor, since "things" in this context does not refer (only) 
to objects or entities, but more broadly to all meaningful data that, as such, register, and can interact, in motion and as motion $[\ldots]$.

Rather than as truth-as-representation, which in order to verify itself requires both the claim and the object of representation to remain static, divinatory truth has a 'motile' ontology- it takes hold by way of the practical movements effected by the diviner that transform diverse paths of existence and meaning. They constitute verdicts whose task is not to conform to ready-given facts, but to connect Ifá myths with the circumstances of the consultant in relevant ways, and in so doing transform different trajectories of meaning. Confronted with such verdicts, the consultant may be bewildered by them, even distressed. Indeed, such may be the appropriate response to the diviner's failure to make a relevant connection between the myths and the personal circumstances of the consultant. But given that divinatory truths are not a matter of representation but one of transformation, such bewilderment is never a 'question of belief' or disbelief in the verdict (Holbraad, 2012: 204). Divinatory truths, in other words, do not exist in relation to a given state of affairs against which they can be 'doubted'. They come into existence in and through motion, and their task is to set meaningful things (including the consultant's life-history and future) in motion. Indeed, belief has nothing to do with it. Divinatory truths are 'indubitable', then, because 'doubt' -which presupposes representation- is irrelevant to them.

Holbraad's study enables us to draw out some important implications of a possible alliance between anthropology and sociology for a decolonial imagination. The first is simple, and it is that just as other realities -and not just other epistemologies- are possible, some of these anthropological studies show that forms of social inquiry that risk imagining the end of epistemology, with its fundamentally representational understanding of knowledge, are possible too. Pace the Kantian tradition, we are not trapped in epistemology. Thus, if "the very separation of sociology and anthropology has facilitated sociology's self-understanding as brought about in the European production of modernity distinct from its colonial entanglements' (Bhambra 2014: 2), my sense is that an alliance with such forms of anthropological inquiry is now crucial for sociology to imagine the end of epistemology without end, and to begin to cultivate a decolonial imagination.

Second, in taking this imaginative leap of thinking beyond epistemology, a recursive implication takes effect- one that affects what we take anthropology and 
sociology themselves to be. Indeed, Holbraad's ethnography is no longer put at the service of 'applying' or confirming the Western concepts of a modern discipline outside the West, nor is his analysis performed with the purpose of interrogating the 'epistemological' assumptions that anthropologists and natives make when they attempt to know practices from the South. By seeking to think from the difference that other practices make, anthropology, and the social sciences more generally, become practices oriented to the construction of 'the conditions for the conceptual, I mean ontological, self-determination of people' (Viverios de Castro, 2003) by affirming, enlarging, and making resonate, the many realities of which the world is made.

Unlike the first two, the second set of implications one can draw from the "turn to ontology' in anthropology are, in my view, negative ones- rather than provide direct paths for inquiry, they might teach us to be vigilant of some of the dangers involved. The first is that the concept of 'ontology' is not itself unequivocal. While an invitation to attend to the ontological in social and cultural practices can be a provocation to traverse the colonial abyss, this needs not be the case. If ontology is defined, for example, as 'theories of being and reality' (Carrithers et al., 2010: 154); if the question is 'how do others think about reality?' instead of 'what realities do others inhabit and how do they enable others to think?', then ontology becomes another word for culture -or indeed, another word for epistemology- and the so-called 'turn to ontology', which claims to be concerned with differences between worlds rather than worldviews, starts to resemble something closer to the study of differences between worldly worldviews.

While I do not think that either Viveiros de Castro or Holbraad fall into such a trap, the concern by some anthropologists that this may be more generally the case is in my view a legitimate one (Carrithers et al., 2010). And it is expounded by the holism that still pervades much anthropological thinking- namely, the tendency to speak of 'ontologies' precisely as one would do of 'cultures', as a matter of 'us' versus 'them', of a 'northern' and a 'southern' ontology, and so on. Thus, rather than propose that sociology take its own 'turn to ontology', I am suggesting that what is at stake in some of these ethnographies is the cultivation of a new form of realism, an alter-realism, for which the very distinction between epistemology and ontology becomes obsolete. A realism that takes the risk of asserting the reality of what is deemed improbable, implausible, marginalised, suppressed, irrelevant, even scandalous, and seeks to draw out its possible implications for the transformation of what is considered credible, reliable, and serious (Savransky, 2016). What would 
become of the (social) sciences were they to take seriously a form of truth that seeks not to represent reality but to set realities in motion?

Finally, there is a political implication that is crucial for how sociology might engage in such forms of realism. Although for Viveiros de Castro (2003) the ontological turn requires that we refrain from thinking 'each culture and society as the embodiment of a specific solution to a generic problem', and that we acknowledge that 'the problems themselves are radically distinct', in the case of many anthropological studies the exercise of creating the conditions for the ontological selfdetermination of people is performed with 'peoples' for whom ontological selfdetermination is not necessarily a problem that demands development. In this sense, a sociological project of 'rearguard' theoretical constructions, that is, of thinking with and after the social and political struggles such as the World Social Forum, the buen vivir movement, and other alter-globalisation, feminist, migration and radical ecological movements, may perhaps serve as an important antidote to this threat. For what is at stake is not just 'peoples' in general, but the construction of theoretical tools for the self-determination of the realities of countermovements and collectives that are already involved in social and political struggles for existential justice. Struggles for a politics of reality that seeks to 'establish forms of life that are simultaneously the effect and the precondition for the continuation of existence of marginalized actors.' (Papadopoulos, 2010: 193). A decolonial, sociological imagination, thus, is one concerned with affirming not only the realities of others, but the realities of others for whom reality itself is in the making, for whom the cry 'another world is possible!' can never be reduced to a simple metaphor.

\section{Conclusion: The Politics of Reality}

Challenging the assumption that epistemology constitutes the proper horizon for the transformative potential that postcolonial and decolonial thought hold for sociology, I have argued that what is at stake is the cultivation of an imagination that can move beyond the concern with how others come to 'know' the world, and can affirm the reality of movements and collectives for whom the possibility of another world matters. The task therefore is to take seriously, and to think with, the differences that these movements have made, and still endeavour to make, in their attempts to actualise the possibilities of another world. To take their struggles seriously is to risk becoming realists again, but not without transforming the stakes of realism itself. It is 
to exercise new decolonial, plural, alter-realisms that enable us to affirm not only the reality of the 'West' -were such a thing to exist- but also other realities in the making. A realism for which 'reality' is, first and foremost, an ethical and political problem.

As I advanced in the introduction, despite his overarching concern with epistemology, I think Santos's concept of the sociology of absences and emergences may prove fertile as a starting point for such a task ${ }^{5}$. We might now be in a position to see why. The reason is that it is in the articulation of this form of sociology that Santos is at his most realist. It is in relation to this proposal that reality itself, and not only epistemology, becomes a political problem. As he puts it,

reality cannot be reduced to what exists because what exists is the only visible part of reality that modern abyssal thinking defines as being on this side of the line and within whose confines it elaborates its theories [...]. Beyond that line, $[\ldots]$ there is nothing of relevance, and it can therefore be easily dismissed or made invisible or irrelevant [or be] produced as nonexistent. The sociology of absences is the inquiry into the workings of this abyssal line in our time. (Santos 2014: 172)

Crucially, to speak of the modern 'production of nonexistence' is not the same as asserting the actual destruction of such alternatives by the established Western régimes of existence. To do so would situate us right back in the colonial abyss, where what we can know can determine what can exist, and where absence of knowledge is equated with nothingness. But absence is not nothingness. No matter how efficacious Modernity may have been in expelling these other existents and their realities off the realm of what is considered plausible, credible, reasonable or even relevant, these nevertheless matter, and they exist 'as meteorites hovering the space of order' (Santos 2014: 171), demanding countermovements to turn them into productive resources for the activation of a politics of reality.

For this reason, the other side of the sociology of absences is a 'sociology of emergences', whose task is that of populating the future with 'plural and concrete possibilities, utopian and realist at one and the same time and constructed in the present by means of activities of care.' (Santos, 2014: 182). A decolonial, sociological project concerned with the politics of reality must therefore cultivate a speculative, pluralist, alter-realism that risks thinking and acting on what is not-yet, on realities to 
be constructed, on futures to be attained. In this way, the possibility of a global sociology, which is to say, of a post-abyssal form of social thought and practice, demands a new kind of imagination, one that allows us to speculatively conceive and to politically affirm 'the South as if there were no North, $[\ldots]$ woman as if there were no man, [...] the slave as if there were no master' (Santos 2014: 171)- and reality as if there were no epistemology. In order to begin to cultivate such a decolonial imagination, we need to risk thinking from the difference that the realities of the South can make, and to put sociology at the service of a politics of reality brought about by such collectives. Whatever 'sociology' becomes in the course of such a task will always remain an open question, for as I have shown, we never 'know' what thinking from the South can do to sociology.

\section{Acknowledgements}

I would like to thank the Boaventura de Sousa Santos and Gurminder Bhambra, as well as the two anonymous reviewers, for their thoughtful comments on a previous version of this article.

\section{Notes}

\footnotetext{
${ }^{1}$ My use of the term 'sociology' here is, to be sure, metonymic. Given sociology's internal heterogeneity, this is no minor point. What I am referring to are those influential traditions of sociological thinking and knowledge-making that have shaped what one may associate with the mainstream of the discipline, while momentarily excluding the intense, if comparatively marginal, zones of exchange between sociology and cultural studies (on this issue see McLennan, 2006).

${ }^{2}$ The other being modern law which, unfortunately, I cannot analyse here in any detail (but see Santos, 2002).

${ }^{3}$ That is, the difference between 'the objectively valid' and the 'merely subjective'. (Daston \& Galison, 2007: 207).

${ }^{4}$ And not because they 'can't', or because they be backward, but because they do not participate in the problem that modern thought has created for knowledge.

${ }^{5}$ Provided that we do not ground it in an 'epistemology of absences' (Santos, 2014: 157)
} 


\section{References}

Alberti B, Fowles S, Holbraad M, et al. (2011) "Worlds Otherwise": Archeology, Anthropology, and Ontological Difference. Current Anthropology 52 (6), 896912

Asad T (1973) Anthropology and The Colonial Encounter. London: Ithaca Press.

Bhaba H (1994) The Location of Culture. London: Routledge.

Bhambra G (2007a) Sociology and Postcolonialism: Another 'Missing' Revolution?. Sociology 41(5), 871-884

Bhambra G (2007b) Rethinking Modernity: Postcolonialism and the Sociological Imagination. Basingstoke \& New York: Palgrave MacMillan.

Bhambra G (2014) Connected Sociologies. London: Bloomsbury.

Braver L (2007) A Thing of This World: A History of Continental Anti-realism. Evanston: Northwestern University Press.

Carrithers M, Candea M, Sykes K, et al. (2010) Ontology is Just Another Word for Culture.

Critique of Anthropology 30(2), 152-200

Chakrabarty D (2000) Provincialising Europe: Postcolonial Thought and Historical Difference. Princeton, NJ: Princeton University Press.

Clifford J (1986) Introduction: Partial Truths. In: Clifford J and Marcus GE (eds) Writing Culture. Berkeley, Los Angeles \& London: University of California Press, 1-26

Clifford J and Marcus GE (1986) Writing Culture: The Poetics and Politics of Ethnography.

Berkeley, Los Angeles \& London: University of California Press.

Connell R (2007) Southern Theory. Cambridge: Polity Press.

Daston L and Galison P (2007) Objectivity. Brooklyn: Zone Books.

Denzin NK, Lincoln YS and Smith LT (2008) Handbook of critical and Indigenous methodologies. Thousand Oaks, CA: Sage.

Durkheim E (1965) The Elementary Forms of Religious Life. New York: Free Press.

Eisenstadt N (2000) Multiple Modernities. Daedalus 129(1), 1-29.

Go J (2013) Postcolonial Sociology. Bingley: Emerald Group Publishing Limited.

Gutiérrez Rodríguez E, Boatcâ M and Costa S (2010) Decolonising European Sociology: Transdisciplinary Approaches. Farnham: Ashgate.

Holbraad M (2012) Truth in Motion: The Recursive Anthropology of Cuban Divination. Chicago: University of Chicago Press.

Kant I (1998) Critique of Pure Reason. Cambridge: Cambridge University Press.

Keim W, Çelik E, Ersche C, et al. (2014) Global Knowledge Production in the Social Sciences. Farnham: Ashgate.

Marx K and Engels F (1998) The German Ideology. Amherst: Prometheus Books. 
McLennan G (2006) Sociological Cultural Studies: Reflexivity and Positivity in the Human Sciences. Basingstoke \& New York: Palgrave Macmillan.

Melliassoux Q (2008) After Finitude: An Essay on the Necessity of Contingency. London: Continuum.

Mignolo W (2009) Epistemic Disobedience, Independent Thought and Decolonial Freedom. Theory, Culture \& Society 26(7-8), 159-181

Mignolo W (2011) The Darker Side of Western Modernity: Global Futures, Decolonial Options. Durham \& London: Duke University Press.

Quijano A (2007) Coloniality and Modernity/Rationality. Cultural Studies 21 (2-3), 168-178

Papadopoulos D (2010) Alter-ontologies: Towards a constituent politics in technoscience.

Social Studies of Science 41(2), 177-201

Said E (1978) Orientalism. London: Penguin.

Santos B (1992) A Discourse on the Sciences. Review 15(1), 9-47

Santos B (2002) Towards a New Legal Common Sense. London: Butterworths.

Santos B (2007) Cognitive Justice in a Global World. Lanham: Lexington Books.

Santos B (2008) Another Knowledge is Possible: Beyond Northern Epistemologies. London: Verso.

Santos B (2014) Epistemologies of the South: Justice Against Epistemicide. Boulder: Paradigm Publishers.

Savransky M (2012) Worlds in The Making: Social Sciences and The Ontopolitics of Knowledge. Postcolonial Studies, 55(3), 351-368

Savransky M (2014) In Praise of Hesitation: 'Global' Knowledge as a Cosmopolitical Adventure. In: Keim W et al. (eds), Global Knowledge Production in the Social Sciences. Farnham: Ashgate, pp.237-250

Savransky M (2016) The Adventure of Relevance: An Ethics of Social Inquiry. London \& New York: Palgrave Macmillan.

Seth S (2013) "Once Blind but Now Can See": Modernity and the Social Sciences. International Political Sociology 7(2), 136-151

Spivak GC (1988) Can the subaltern speak? In: Nelson C and Grossberg L (eds.) Marxism and the interpretation of culture. Chicago: University of Illinois Press, 271-316

Viveiros de Castro E (1998) Cosmological Deixis and Amerindian Perspectivism. The Journal of the Royal Anthropological Institute 4(3), 469-488

Viveiros de Castro E (2003) AND. Manchester Papers in Social Anthropology. Available at: https://sites.google.com/a/abaetenet.net/nansi/abaetextos/anthropology-and$\underline{\text { science-e-viveiros-de-castro }}$

Viveiros de Castro E (2004) Perspectival Anthropology and the Method of Controlled Equivocation. Tipití: Journal of the Society for the Anthropology of Lowland South America 2(1), 3-20 
Viveiros de Castro E (2014) Cannibal Metaphysics. Minneapolis: Univocal.

Wallerstein I (1996) Eurocentrism and Its Avatars: The Dilemmas of Social Science. New Left Review 226 (I), 93-107

Weber M (1949) The Methodology of the Social Sciences. New York: Free Press.

Whitehead AN (1978) Process and Reality. New York: Free Press.

\section{Author Biography}

Martin Savransky is Lecturer at the Department of Sociology, Goldsmiths, University of London, where he teaches philosophy, social theory, and the philosophy of the social sciences. He is the author of The Adventure of Relevance (Palgrave Macmillan, with a foreword by Isabelle Stengers), and co-editor of Speculative Research: The Lure of Possible Futures (Routledge, forthcoming). 